\title{
CARDIAC MRI: THE KEY TO RELEASE THE JAILED HEART
}

\author{
Nandhakumar Vasu1, Srinivasan Narayanan², Kalaichelvan Uthayakumaran³, Balaji Pakshirajan, Mullasari S. Ajit5
}

${ }^{1}$ Associate Consultant, Institute of Cardio-Vascular Diseases, The Madras Medical Mission, Chennai.

${ }^{2}$ Consultant, Institute of Cardio-Vascular Diseases, The Madras Medical Mission, Chennai.

${ }^{3}$ Consultant, Institute of Cardio-Vascular Diseases, The Madras Medical Mission, Chennai.

${ }^{4}$ Consultant, Institute of Cardio-Vascular Diseases, The Madras Medical Mission, Chennai.

5Director, Institute of Cardio-Vascular Diseases, The Madras Medical Mission, Chennai.

\begin{abstract}
The diagnosis of Constrictive Pericarditis (CP) is based on thickened pericardium and demonstration of constrictive physiology by various imaging and cardiac catheterisation. We report a case of Elastic CP with normal thickening, but CP physiology demonstrated by cardiac MRI.
\end{abstract}

\section{KEYWORDS}

Elastic constriction, MRI, Pericarditis.

HOW TO CITE THIS ARTICLE: Vasu N, Narayanan S, Uthayakumaran K, et al. Cardiac MRI: the key to release the jailed Heart. J. Evolution Med. Dent. Sci. 2016;5(79):5927-5928, DOI: 10.14260/jemds/2016/1338

A 65 years old female presented with leg swelling and abdominal distension and on clinical examination patient had bilateral pedal oedema and ascites. Jugular venous pressure was elevated with prominent $\mathrm{V}$ wave, $\mathrm{X}$ and $\mathrm{Y}$ descents and Kussmaul sign was present. Pericardial knock was heard on cardiac auscultation. She had been suffering from rheumatoid arthritis since 25 years. Chest X-ray and ECG showed features of biatrial enlargement. The echocardiogram revealed biatrial enlargement, preserved systolic and diastolic function, normal pulmonary artery systolic pressures, interventricular septal bounce and a more than $25 \%$ respiratory variations in the mitral inflow. There was an expiratory diastolic flow reversal on the hepatic vein pulse Doppler. Computed tomogram of heart revealed upper normal limit of pericardial thickness about 3-4 $\mathrm{mm}$ without calcification. The cardiac Magnetic Resonance Imaging (MRI) with $20 \mathrm{~mL}$ of gadolinium contrast enhancement showed the thickness of the pericardium as 4 mm [Figure 1A]. It demonstrated the diagnostic CP physiology [Figure-1B, 1C \& 1D] namely dissociation of intrathoracic and intracardiac pressures and exaggerated interventricular dependence as septal bounce was seen in MRI (Video-1). The inferior venacava, superior venacava and both the atria were dilated. The Right Ventricle (RV) and Left Ventricle (LV) ejection fractions were $70 \%$ and $73 \%$ respectively. The end diastolic volumes of the RV and $\mathrm{LV}$ were $31 \mathrm{~mL} / \mathrm{m}^{2}$ (normal range of $41-87 \mathrm{~mL} / \mathrm{m}^{2}$ ). Contrast perfusion studies did not show any area of poor perfusion at rest. The delayed enhancement images post-contrast revealed enhancement all around the $\mathrm{LV}, \mathrm{RV}$ and the $\mathrm{AV}$ groove suggesting inflammation or fibrosis.

Financial or Other, Competing Interest: None.

Submission 26-08-2016, Peer Review 19-09-2016,

Acceptance 25-09-2016, Published 03-10-2016.

Corresponding Author:

Dr. Nandhakumar Vasu,

\#4-A, DR. J. J. Nagar,

Institute of Cardio-Vascular Diseases,

The Madras Medical Mission,

Mogappair

Chennai-600037.

E-mail: nandhacard2013@gmail.com,nandhapaed1982@gmail.com DOI: $10.14260 /$ jemds $/ 2016 / 1338$

\section{(c) (i) $(9)$}

The myocardium was normal. Cardiac catheterisation showed end diastolic equalisation of pressures in all 4 chambers, more than $25 \%$ respiratory variations in the mitral inflow pattern [Figure-2A], early diastolic dip and plateau pattern (Square root sign) [Figure 2B] and normal pulmonary artery systolic pressures. ${ }^{1}$

The most specific and sensitive inspiratory to expiratory $\mathrm{RV} / \mathrm{LV}$ systolic pressure-time area index [Figure 2B] was 1.6 $(0.16 / 0.10)$ which favoured Constrictive Pericarditis (CP). ${ }^{2}$ Patient underwent pericardiectomy with an uneventful perioperative period (Figure 3). The pathology report showed borderline thickening of pericardium with fibrosis and chronic inflammation without calcification, necrosis or granulomas.

Cardiac MRI provides information about anatomy, pericardial thickness, systolic and diastolic functions, chamber volumes, respiratory variation of haemodynamics and myocardial texture accurately. It is the most important tool to differentiate constrictive pericarditis from restrictive cardiomyopathy. Non-tuberculous Elastic CP can present with typical CP physiology without much thickening and calcification. ${ }^{3}$ MRI lightens Elastic $\mathrm{CP}$ and help to take a call to release the heart from jailed pericardium.

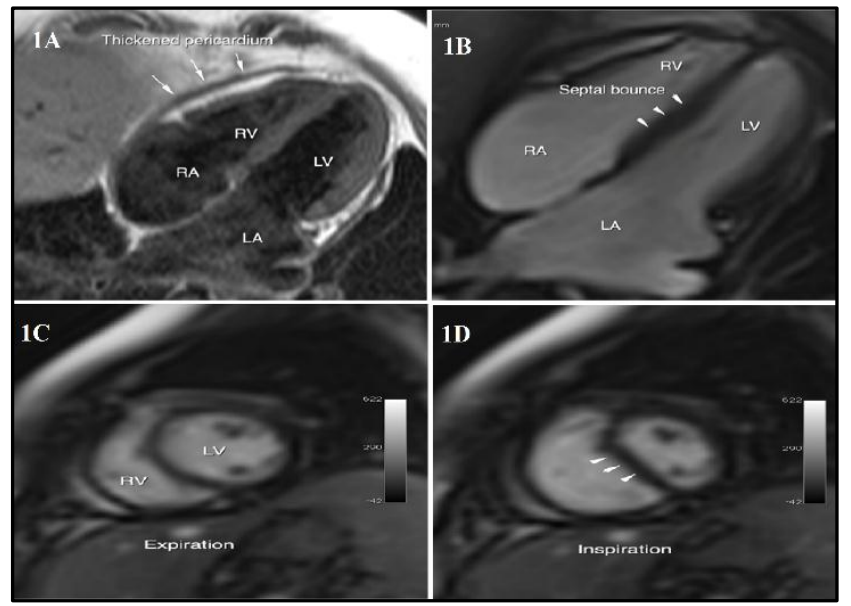

Fig. 1: Cardiac MRI. 1A-Borderline Thickening of Pericardium $4 \mathrm{~mm}$. 1B-Four Chamber View and $1 C \& 1 D$ Short Axis View shows Septal Bounce 

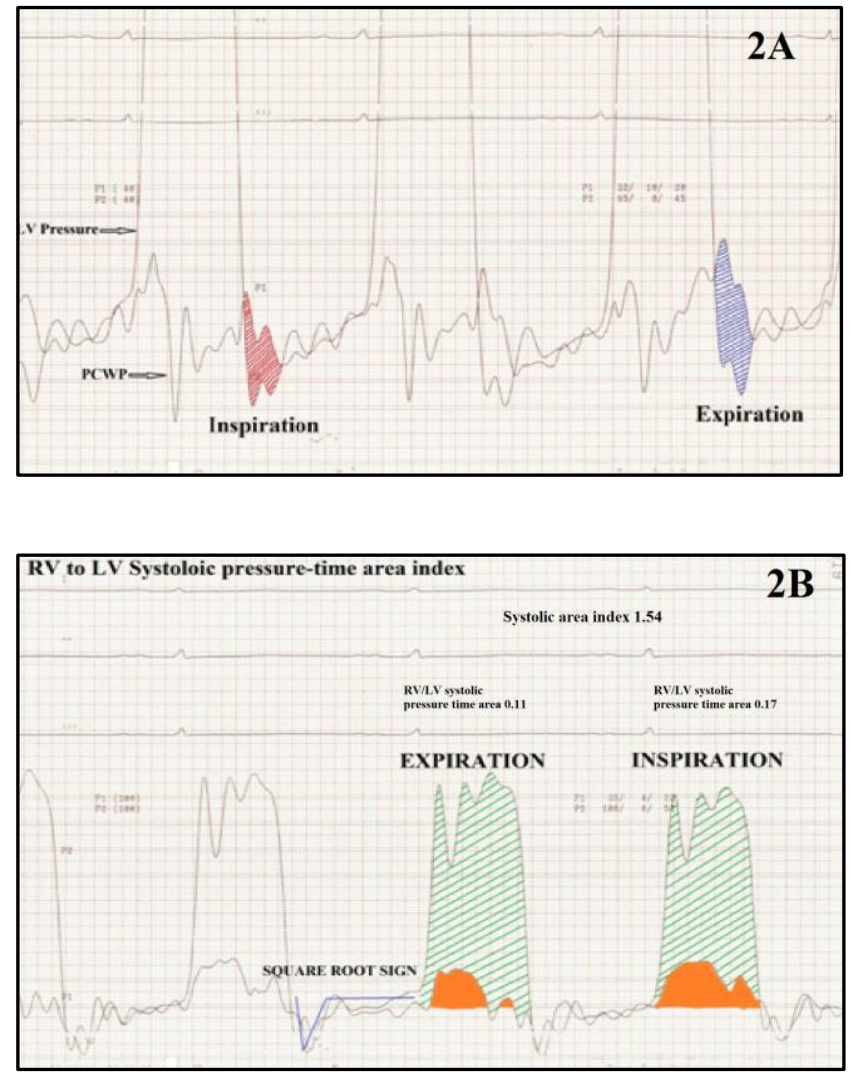

Fig. 2: Cardiac Catheterisation. 2A-More than 25\% Mitral Inflow Variation during Respiration. 2B-Right Ventricle to Left Ventricle Inspiration and Expiration Systolic Pressure Time Area Index and Square Root Sign

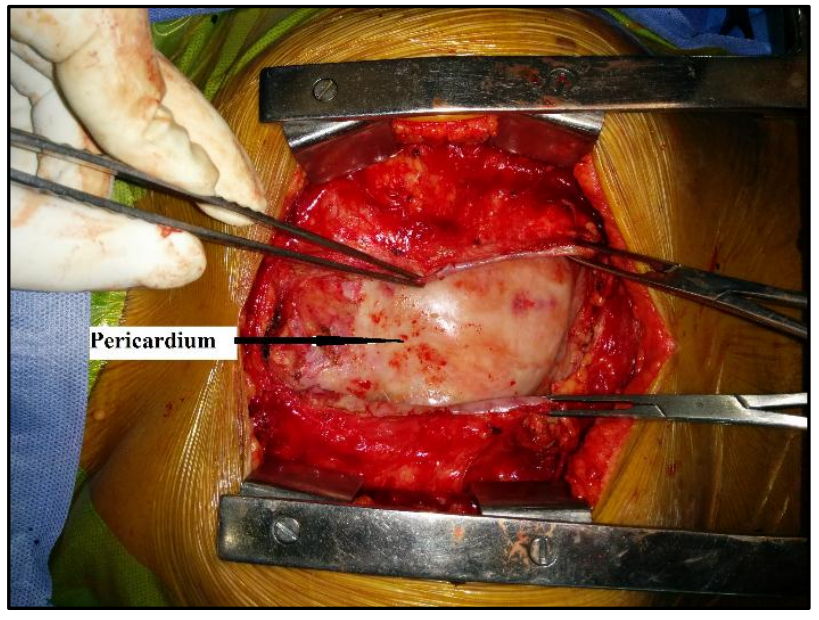

Fig. 3: Removal of Pericardium during Surgery

\section{REFERENCES}

1. Yu PN, Lovejoy FW, Joos HA, et al. Right auricular and ventricular pressure patterns in constrictive pericarditis. Circulation 1953;7:102-7.

2. Talreja DR, Nishimura RA, Oh JK, et al. Constrictive pericarditis in the modern era. Novel criteria for diagnosis in the cardiac catheterization laboratory. Journal of the American College of Cardiology 2008;51(3):315-9.

3. Talreja DR, Edwards WD, Danielson GK, et al. Constrictive pericarditis in 26 patients with histologically normal pericardial thickness. Circulation 2003;108(15):1852-7. 